\title{
Optimization of banana trunk-activated carbon production for methylene blue-contaminated water treatment
}

\author{
Mohammed Danish ${ }^{1} \cdot$ Tanweer Ahmad $^{2}$ - W. N. A. W. Nadhari ${ }^{1} \cdot$ Mehraj Ahmad $^{3}$ - Waheed Ahmad Khanday ${ }^{4}$. \\ Lou Ziyang ${ }^{5} \cdot$ Zhou Pin $^{5}$
}

Received: 7 January 2017 / Accepted: 6 November 2017 / Published online: 24 January 2018

(c) The Author(s) 2018. This article is an open access publication

\begin{abstract}
This experiment was run to characterize the banana trunk-activated carbon through methylene blue dye adsorption property. The $\mathrm{H}_{3} \mathrm{PO}_{4}$ chemical activating agent was used to produce activated carbons from the banana trunk. A small rotatable central composite design of response surface methodology was adopted to prepare chemically $\left(\mathrm{H}_{3} \mathrm{PO}_{4}\right)$ activated carbon from banana trunk. Three operating variables such as activation time (50-120 min), activation temperature $\left(450-850{ }^{\circ} \mathrm{C}\right)$, and activating agent concentration $(1.5-7.0 \mathrm{~mol} / \mathrm{L})$ play a significant role in the adsorption capacities $(q)$ of activated carbons against methylene blue dye. The results implied that the maximum adsorption capacity of fixed dosage $(4.0 \mathrm{~g} / \mathrm{L})$ banana trunk-activated carbon was achieved at the activation time of $51 \mathrm{~min}$, the activation temperature of $774{ }^{\circ} \mathrm{C}$, and $\mathrm{H}_{3} \mathrm{PO}_{4}$ concentration of $5.09 \mathrm{~mol} / \mathrm{L}$. At optimum conditions of preparation, the obtained banana trunk-activated carbon has adsorption capacity $64.66 \mathrm{mg} / \mathrm{g}$ against methylene blue. Among the prepared activated carbons run number 3 (prepared with central values of the operating variables) was characterized through Fourier transform infrared spectroscopy, field emission scanning microscopy, and powder X-ray diffraction.
\end{abstract}

Keywords Activated carbon $\cdot$ Banana trunk $\cdot$ Chemical activation $\cdot$ Optimization $\cdot$ Adsorption capacity

\section{Introduction}

Dyes are extensively used in many industries, such as in textile, leather, paper, wool, printing and cosmetics. The release of wastewater containing dye compounds into water sources

Tanweer Ahmad

tanweerakhan@gmail.com

1 Universiti Kuala Lumpur Malaysian Institute of Chemical and Bio-engineering and Technology (MICET), Universiti Kuala Lumpur, Lot 1988, Kaw. Per. Bandar Vendor, Taboh Naning, 78000 Alor Gajah, Malacca, Malaysia

2 Department of Chemistry, College of Natural and Computational Science, Madda Walabu University, Bale-Robe, Ethiopia

3 Institute of Nutrition (INMU), Mahidol University, 999 Phutthamonthon 4 Rd., Salaya, Nakhon Pathom 73170, Thailand

4 School of Chemical Engineering, Universiti Sains Malaysia, 14300 Nibong Tebal, Penang, Malaysia

5 School of Environmental Science and Engineering, 800 Dongchuan Road, Shanghai Jiao Tong University, Shanghai 200240, China has caused a severe environmental impact. As dyeing effluent will deplete the dissolved oxygen content in water and also inhibit sunlight from reaching to the water sources, some of the dye wastewater is usually poisonous and carcinogenic to human beings (Bhattacharya and Sharma 2005). Thus, the removal of dyes from wastewater is necessary before discharging into water bodies. Methylene blue (MB), an aromatic heterocyclic compound, was extensively used in a range of different fields, especially in textile industry. The wastewater containing MB has adverse impacts on flora, fauna and aquatic ecosystems (Ghosh and Bhattacharyya 2002; Guo et al. 2014). Moreover, MB is frequently used as a probe molecule for determining the adsorption capacity of adsorbents (Bestani et al. 2008). Therefore, it is essential to minimize a number of dyes to the lowest possible limit approved by the environment and health agencies. A wide range of methods has been adopted for the treatment of wastewater containing dye residues, such as coagulation, ozonation, irradiation, flocculation, electrochemical destruction, electrokinetic, membrane filtration, photocatalytic oxidation, ion exchange and adsorption on a solid phase. 
Adsorption is a cost-effective and user-friendly technique for the removal of existing dyes (Danish et al. 2014a).

Activated carbon is carbonaceous material that has highly developed porosity, internal surface area, and relatively high mechanical strength. They are extensively used as an adsorbent in wastewater and gaseous pollutant removal. Due to these features, the demand for activated carbon is increasing day by day. The activated carbon can be produced from a variety of natural and synthetic substances. The ligno-cellulosic material is the most commonly used precursor for the synthesis of activated carbon. The composition of the lignocellulosic materials determines to some extent, the porosity development of the produced activated carbons (Valente Nabais et al. 2013). The production of activated carbon from agricultural by-products has received much attention from the scientific community as they are renewable, low-cost and environmentally friendly materials (Okman et al. 2014). A large number of agricultural by-products, such as date stone (Danish et al. 2014b), Acacia mangium wood (Danish et al. 2011), cocoa shell (Ahmad et al. 2012), waste tea (Auta and Hameed 2011), coffee husks (Oliveira et al. 2009), pomegranate wood (Ghaedi et al. 2015), mahogany sawdust (Malik 2003), rice husk (Malik 2003), corn cob (Sych et al. 2012), and other materials have been successfully used for the production of low-cost activated carbon.

The biggest challenge in the activated carbon production from new precursors is to produce very specific carbons which are suitable for particular applications. An essential characteristic of activated carbon is its adsorption capacity which is highly influenced by the preparation conditions. Meanwhile, in assessing the effect of the preparation conditions on quality aspects, the use of an adequate experimental design is particularly very important. Response surface methodology (RSM) has been used as a tool to identify the interactions of two or more variables (Ranjan et al. 2011; Karacan et al. 2007).

This experiment was designed to find the optimum variables such as activating agent concentration, activation temperature, and activation time for the production of activated carbon from the banana trunk by chemical activation. The response of the designed experiment was evaluated through adsorption capacity against methylene blue. An attempt has been made to use banana trunk, an abundantly available ligno-cellulosic agricultural waste, as a cheap and renewable precursor for activated carbon preparation.

\section{Materials and methods}

\section{Banana trunk collection and sample preparation}

The banana trunk was collected from banana plantation garden located in Durian Tunggal, Melaka, Malaysia. The collected trunk was cut into smaller pieces for fast drying. After sun drying for 2 days, the partially dried banana trunk pieces were kept in the hot air oven at $105{ }^{\circ} \mathrm{C}$ for $24 \mathrm{~h}$ to make it uniformly dried at minimum possible moisture level $(\sim 6 \%)$. After drying, the sample was kept in desiccators to get the cooling free from gaining back moisture. These dried samples were ground into powder and sieved to get a uniform particle size of $0.5 \mu \mathrm{m}$. The flow of banana trunk drying and conversion into activated carbon are schematically represented in Fig. 1.

\section{Preparation of activated carbon from banana trunk powder using response surface methodology (RSM)}

The preparation of activated carbon was carried out based on three parameters such as activation time, activation temperature, and concentration of phosphoric acid. Ten grams of banana trunk powder was mixed well with $20 \mathrm{~mL}$ of desired concentration of $\mathrm{H}_{3} \mathrm{PO}_{4}$ solutions (85\% orthophosphoric acid was purchased from MERCK Germany). The mixing was performed at room temperature. The capped crucibles containing soaked banana trunk powder were placed inside a muffle furnace (CARBOLITE CWF 1200) at a set temperature for a fixed period. The combination of different activation time, temperature, and concentration of $\mathrm{H}_{3} \mathrm{PO}_{4}$ was done according to Table 1 . The crucibles were left inside the furnace for $24 \mathrm{~h}$ to cool down at room temperature. The prepared activated carbon was washed with hot and cold water to remove the adhered water soluble byproducts such as $\mathrm{P}_{2} \mathrm{O}_{5}$ and un-reacted chemical agents. After that, it was dried in hot air oven for $24 \mathrm{~h}$, weighed and packed in sealable plastic bags for further use.

\section{Design of experiments for the preparation of activated carbon}

Response surface methodology (RSM) is a statistical technique that uses quantitative data from the experiments to develop a regression model relating the experimental response to the process variables (Jaiswal et al. 2011; Alam et al. 2007). A small rotatable central composite design (CCD) of response surface methodology was utilized to plan the number of experiments with a different combination of operating variables to optimize the activated carbon preparation conditions. This method is appropriate for fitting a quadratic surface design, and it helps to optimize the variables with a minimum number of experiments, as well as to analyze the interaction between the variables (Azargohar and Dalai 2005). The independent variables selected in the present study were activation time $\left(X_{1}\right)$, activation temperature $\left(X_{2}\right)$ and $\mathrm{H}_{3} \mathrm{PO}_{4}$ concentration $\left(X_{3}\right)$. A small factorial $\mathrm{CCD}$ for the three variables, consisting of 6 factorial points, 4 axial points, and 5 replicates at the center points 


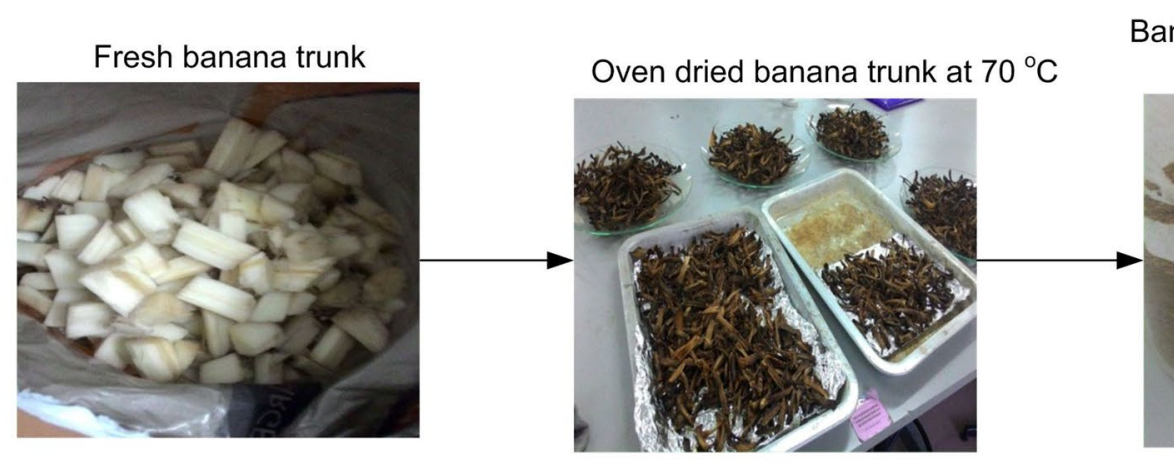

Banana trunk powder with size

Oven dried $\mathrm{AC}$ at $105^{\circ} \mathrm{C}$ after washing

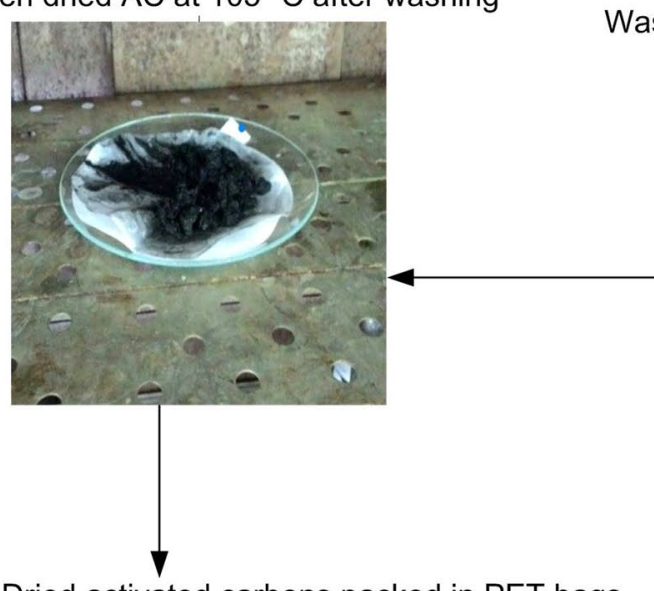

Washing with hot and cold water

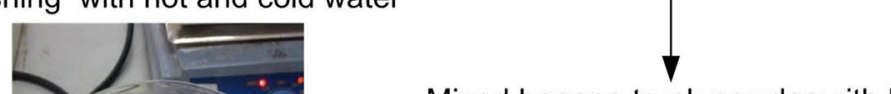

Mixed banana trunk powder with $\mathrm{H}_{3} \mathrm{PO}_{4}$

Dried activated carbons packed in PET bags
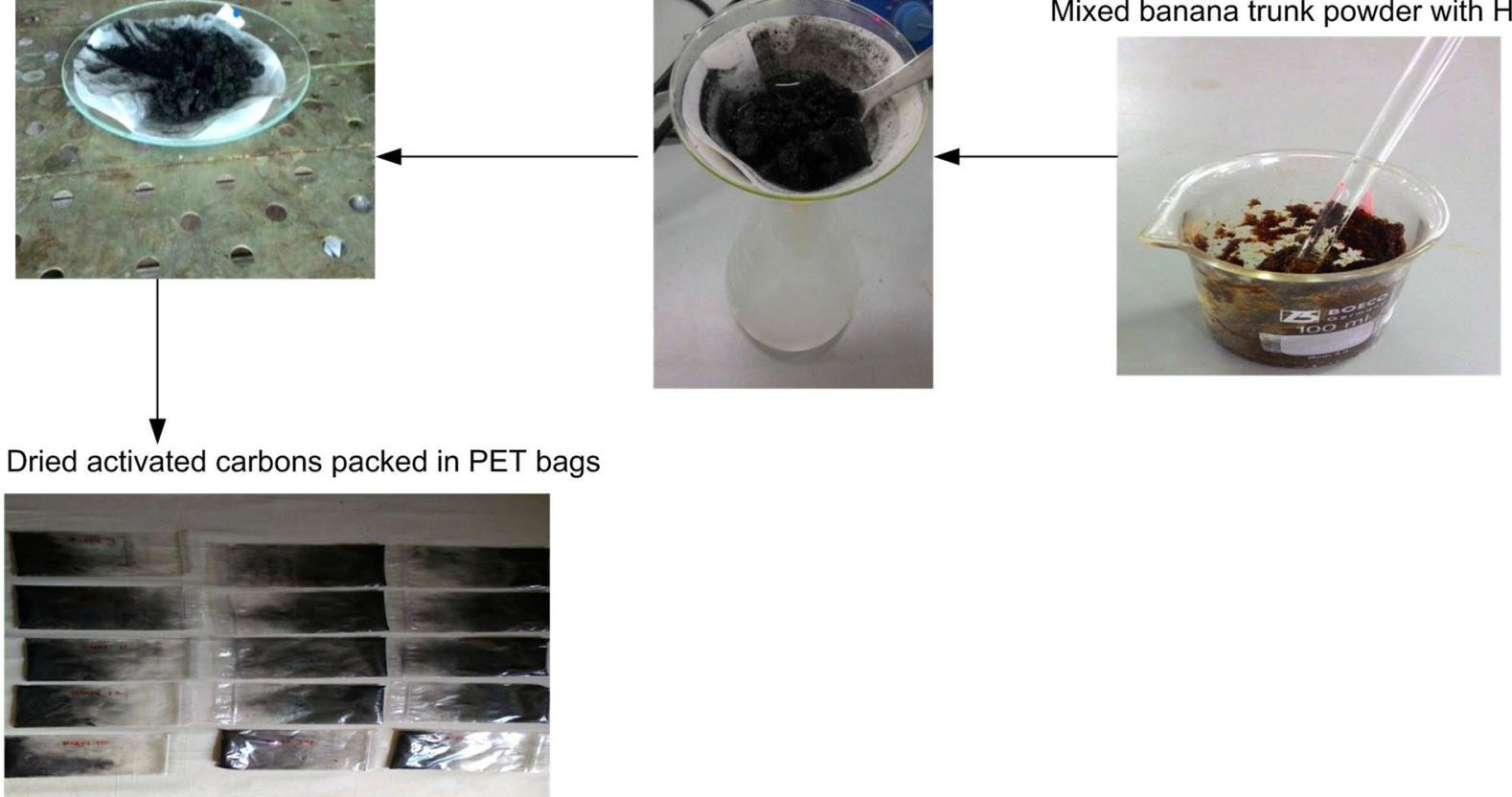

Fig. 1 Schematic representation of banana trunk drying and its conversion into activated carbon

Table 1 Levels and ranges of independent variables used during the experiments

\begin{tabular}{lllllll}
\hline Parameters & Factors & \multicolumn{2}{l}{ Variable level } & & \\
\cline { 3 - 7 } & & -1.414 & -1 & 0 & 1 & 1.414 \\
\hline Time of activation (min) & $X_{1}$ & 35.5 & 50 & 85.0 & 120 & 134.5 \\
$\begin{array}{l}\text { Temperature }\left({ }^{\circ} \mathrm{C}\right) \\
\begin{array}{c}\text { Activating agent concentration } \\
(\mathrm{mol} / \mathrm{L})\end{array}\end{array}$ & $X_{2}$ & 367 & 450 & 650 & 850 & 932 \\
& $X_{3}$ & 0.36 & 1.5 & 4.25 & 7.00 & 8.14 \\
\end{tabular}

are employed, with a total of 15 experiments calculated from the equation below (Azargohar and Dalai 2005):

$N=2^{n-1}+2 n+n_{\mathrm{c}}=2^{2}+(2 \times 3)+5=15$.

The levels and ranges of the variables that affect the adsorption capacity during the activation process of the banana trunk-activated carbons are given in Table 1 . The experiments were planned to run between the selected ranges of each variable. The star values $( \pm 1.414)$ were considered for each parameter to test the effect of each parameter on adsorption capacity when their values extrapolated below the lowest values and above the highest value. This method will give the freedom to find the optimum outside the selected range if it lies above or below the range. 


\section{Model fitting and statistical analysis}

The design-Expert 6.0.6 Stat-Ease, Inc., Minneapolis, USA software was used for model fitting and statistical analysis such as regression analysis of experimental data to fit the empirical equation and three-dimensional (3D) plots of the response surface. The analysis of variance (ANOVA) for experimental data was also calculated using the same software.

\section{Methylene blue adsorption study}

A 1000 ppm methylene blue $\left(\mathrm{C}_{16} \mathrm{H}_{18} \mathrm{ClN}_{3} \mathrm{~S}\right.$, Molar mass: $319.85 \mathrm{gm} / \mathrm{mol}$, procured from R \& M Chemicals, Malaysia) dye solution was prepared in $1 \mathrm{~L}$ and used as a stock solution. The desired concentrations were prepared by the dilution of the stock solution. In this experiment, $20 \mathrm{~mL}$ of $150 \mathrm{ppm}$ methylene blue dye solution were used with $0.05 \mathrm{~g}$ of activated carbon (adsorbent dose $2.5 \mathrm{~g} / \mathrm{L}$ ), kept it for constant agitation for $24 \mathrm{~h}$. After filtration, the solid activated carbon was separated, and the liquid was tested for methylene blue concentration using UV-Vis spectroscopy (Perkin Elmer Lambda EZ210) at lambda max. $664 \mathrm{~nm}$. Before testing the unknown concentration, the standard curve was plotted with standard solutions of known concentrations, i.e., 0.0, 0.1, 0.5, 1.0, 1.5, and $2.0 \mathrm{ppm}$. The linearity of the standard curve was found to be 0.9942 . The adsorption capacity of the banana trunkactivated carbon was calculated by the following equation:

$q(\mathrm{mg} / \mathrm{g})=\frac{\left(C_{\mathrm{i}}-C_{\mathrm{f}}\right)}{2.5}$,

where $C_{\mathrm{i}}$ and $C_{\mathrm{f}}$ are initial and final concentration $(\mathrm{mg} / \mathrm{L})$ of the methylene blue dye.

\section{Characterization of the banana trunk-activated carbon}

The banana trunk-activated carbon prepared at central values $(0,0,0)$ of the independent variables was selected for characterization study. The Fourier transform infrared spectroscopy (FTIR), Field emission scanning electron microscopy (FESEM), and Powder X-ray diffraction techniques were used to characterize the activated carbon sample.

\section{Result and discussion}

\section{Effect of preparation variables on adsorption capacity}

The adsorption capacity of the banana trunk-activated carbon was significantly affected by the preparation parameters of the activated carbon. On applying the adsorption capacity data on the central composite design model, a quadratic model was suggested to explain the effect of operating parameters such as time of activation, temperature of activation, and activating agent concentration. The change in preparation variables and the corresponding adsorption capacity of the banana trunk-activated carbon was correlated through the second-order model. The layout of the design is shown in Table 2 , along with the adsorption capacity experimental data. The run numbers of 1, 3, 5, 8, 12, and 15 were used to determine the experimental deviation. Based on the highest order polynomial, the sum of model squares was determined. Regression analysis was run to fit the response function adsorption capacity (mg/g). The empirical model regarding actual variables after excluding the insignificant variables for methylene blue adsorption capacity is given in below equation.

$q$ (methylene blue, $\mathrm{mg} / \mathrm{g})=$

$$
\begin{aligned}
& 59.51-0.17 x_{1}+0.088 x_{2}-6.93 x_{3}-0.13 x_{1}^{2}+0.013 x_{2}^{2} \\
& -4.95 x_{3}^{2}-11.77 x_{1} x_{2}-4.84 x_{1} x_{3}-5.23 x_{2} x_{3},
\end{aligned}
$$

Table 2 Experimental design matrix for preparation of activated carbon

\begin{tabular}{lrrrl}
\hline Run & \multicolumn{2}{l}{ Variables } & & Responses \\
\cline { 2 - 4 } & \multicolumn{1}{c}{$X_{1}$} & \multicolumn{1}{l}{$X_{2}$} & \multicolumn{1}{c}{$X_{3}$} & $\begin{array}{l}Y \text { (adsorption } \\
\text { capacity, mg/g) }\end{array}$ \\
\hline 1 & 1.414 & 0.000 & 0.000 & 39.69 \\
2 & -1.000 & 1.000 & 1.000 & 39.74 \\
3 & 0.000 & 0.000 & 0.000 & 59.59 \\
4 & 0.000 & 0.000 & 0.000 & 58.81 \\
5 & 0.000 & 0.000 & -1.414 & 59.59 \\
6 & -1.414 & 0.000 & 0.000 & 58.93 \\
7 & 0.000 & 0.000 & 1.414 & 59.35 \\
8 & 0.000 & 0.000 & 0.000 & 59.41 \\
9 & 0.000 & 0.000 & 0.000 & 59.84 \\
10 & -1.000 & -1.000 & -1.000 & 59.34 \\
11 & 0.000 & 0.000 & 0.000 & 59.72 \\
12 & 1.000 & -1.000 & 1.000 & 59.49 \\
13 & 0.000 & -1.414 & 0.000 & 59.48 \\
14 & 0.000 & 1.414 & 0.000 & 59.67 \\
15 & 1.000 & 1.000 & -1.000 & 59.21 \\
\hline
\end{tabular}


where $x_{1}, x_{2}$, and $x_{3}$ are the time of activation, the temperature of activation, and activating agent concentration, respectively.

The effect of a variable on the formation of activated carbon from the banana trunk with considerably good adsorption capacity has been visualized through the above equations. For variables in coded terms $(1.414,0,0)$ and $(-1,1$, $1)$, the adsorption capacity was around $39 \mathrm{mg} / \mathrm{g}$; whereas, for variables $(0,0,-1.414)$ and $(1,1,-1)$, the adsorption capacity was around $59 \mathrm{mg} / \mathrm{g}$ (Table 2). These results showed that the optimized value of the variables viz. activating agent concentration, activation temperature, and activation time for maximum adsorption capacity of activated carbon falls within these experiments.

\section{Analysis of variance (ANOVA)}

To further justify how adequate the models are, analysis of variance (ANOVA) was applied. Table 3 shows the ANOVA values for the model and the process factors. The models $F$ value of 500.85 implies that the model is statistically significant (Prob. $>F$ value 0.0001 ), there is only a chance of $0.01 \%$ for this large $F$ value to occur due to noise. The variables $X_{1}, X_{2}, X_{3}, X_{2}^{2}, X_{3}^{2}, X_{1} X_{2}, X_{1} X_{3}$ and $X_{2} X_{3}$ were found to be significant in the designed statistical model (as given in Eq. 3). The "Prob. $>F$ " for variables greater than 0.100, implied that model variables are not significant and these variables can be removed from the model to improve the mathematical model.

The "lack of fit" $F$ value for the percentage adsorption capacity was calculated to be 0.31 ; this implies that the "lack of fit" was non-significant statistically relative to the pure error. The lack of fit data was non-significant (Prob. $>F$ value 0.6056 ); the model and 'lack of fits' having "Prob. $>F$ " values $<0.05$ are considered to be as potentially significant. The non-significant "lack of fit" is desired to be statistically valid model. Hence, the proposed model is valid. The "Adeq Precision" measures the signal to noise ratio. A ratio greater than four is desirable. For the designed model, it was calculated 63.45 for adsorption capacity. This showed that the current model had an adequate signal and can be used to navigate the design space above and below the selected range of operating factors. Moreover, the "Pre

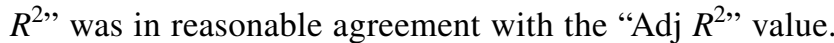
The values of $R^{2}$ and adj $R^{2}$ for adsorption capacity were found to be 0.9989 and 0.9969 , respectively. These values verified the linearity between the model's calculated results and experimental data for adsorption capacity. For percentage adsorption capacity, the model $F$ value was 500.85 , which implies that the model is significant.

\section{Response surface plots}

Three-dimensional (3D) response surface plots were used to explain the behavior of system variables within the design of the experiment. It can facilitate an inspection of experimental factors in selected responses like adsorption capacity (Hasan and Srivastava 2011; Danish et al. 2014b). Therefore, 3D response surface curves were plotted for a statistically significant model to explore the interaction of variables on the adsorption capacity of the produced activated carbon. The 3D plots help in interpreting the interaction of two
Table 3 Analysis of variance for selected factorial model for adsorption capacity

\begin{tabular}{lllllc}
\hline Source & Sum of squares & $\begin{array}{l}\text { Degree of } \\
\text { freedom }\end{array}$ & Mean square & $F$ value & Prob $>F$ \\
\hline $\begin{array}{l}\text { For adsorption capacity }\left(R^{2}=0.9989, \text { adj }\right. \\
\text { dev. }=0.39, \text { C.V. }=0.68, \text { mean }=56.81)\end{array}$ & & & \\
Model & $6.74 \times 10^{2}$ & 9 & 74.95 & 500.85 & $<0.0001^{*}$ \\
$X_{1}$ & 0.12 & 1 & 0.12 & 0.77 & 0.4204 \\
$X_{2}$ & 0.031 & 1 & 0.031 & 0.21 & 0.6669 \\
$X_{3}$ & 192.28 & 1 & 192.28 & 1284.91 & $0.0001^{*}$ \\
$X_{1}^{2}$ & 0.14 & 1 & 0.14 & 0.93 & 0.3790 \\
$X_{2}^{2}$ & $1.33 \times 10^{-3}$ & 1 & $1.33 \times 10^{-3}$ & $8.91 \times 10^{-3}$ & 0.09285 \\
$X_{3}^{2}$ & 188.78 & 1 & 188.78 & 1261.54 & $0.0001^{*}$ \\
$X_{1} X_{2}$ & 276.86 & 1 & 276.86 & 1850.17 & $0.0001^{*}$ \\
$X_{1} X_{3}$ & 46.83 & 1 & 46.83 & 312.97 & $0.0001^{*}$ \\
$X_{2} X_{3}$ & 54.75 & 1 & 54.75 & 365.89 & $0.0001^{*}$ \\
Residual & 0.75 & 5 & 0.15 & & 0.6056 \\
Lack of fit & 0.054 & 1 & 0.054 & 0.31 & \\
Pure error & 0.69 & 4 & 0.17 & & \\
Correlation total & $6.75 \times 10^{2}$ & 14 & & & \\
\hline
\end{tabular}

*Indicates significant values 
operating factors simultaneously. The graphical representation of the mathematical models as in Eq. (3) facilitates an examination of the effects of the operating factors on the adsorption capacity. The quadratic plots of adsorption capacity shown in Fig. 2a-c. It can be clearly seen from the response surface 3D plot that adsorption capacity was significantly affected by the selected variables. The preparation of activated carbons from the raw banana trunk was mainly guided by the three process variables such as time of activation, activation temperature, and $\mathrm{H}_{3} \mathrm{PO}_{4}$ concentration. These independent variables have their own effects on the physical, textural characteristics, and adsorption capacity of the prepared activated carbons. The following sections explain the combined effects of variables on the adsorption capacity of the activated carbons.

\section{Effect of activation time and temperature}

The interaction of activation time and temperature at fixed activating agent dose for adsorption capacity has a curvature in response surface plot as shown in Fig. 2a. The methylene blue adsorption capacity achieves a maximum value of $71.4 \mathrm{mg} / \mathrm{g}$ when the activated carbon is prepared either at minimum activation time and maximum activation temperature or at maximum activation time and minimum activation temperature conditions. Whereas, at minimum activation time and minimum activation temperature or maximum activation time and maximum activation temperature, the adsorption capacity was found lower. The activated carbon adsorption capacity against methylene blue achieved maximum value when the temperature of the activation was the highest (at $850^{\circ} \mathrm{C}$ ) and the time taken to prepare that activated carbon was only 50 min which was the lowest value of activation time. The other condition for preparing the higher adsorption capacity activated carbon was activation time $120 \mathrm{~min}$ and activation temperature $450{ }^{\circ} \mathrm{C}$ at a constant $\mathrm{H}_{3} \mathrm{PO}_{4}$ concentration $(4.25 \mathrm{~mol} / \mathrm{L})$. These results can be interpreted as, at a low temperature of activation, the banana trunk biomass needs longer time to generate pores in the activated carbons suitable for the adsorption of methylene blue, and at a higher temperature of activation pores generated in the activated carbons in a shorter time.
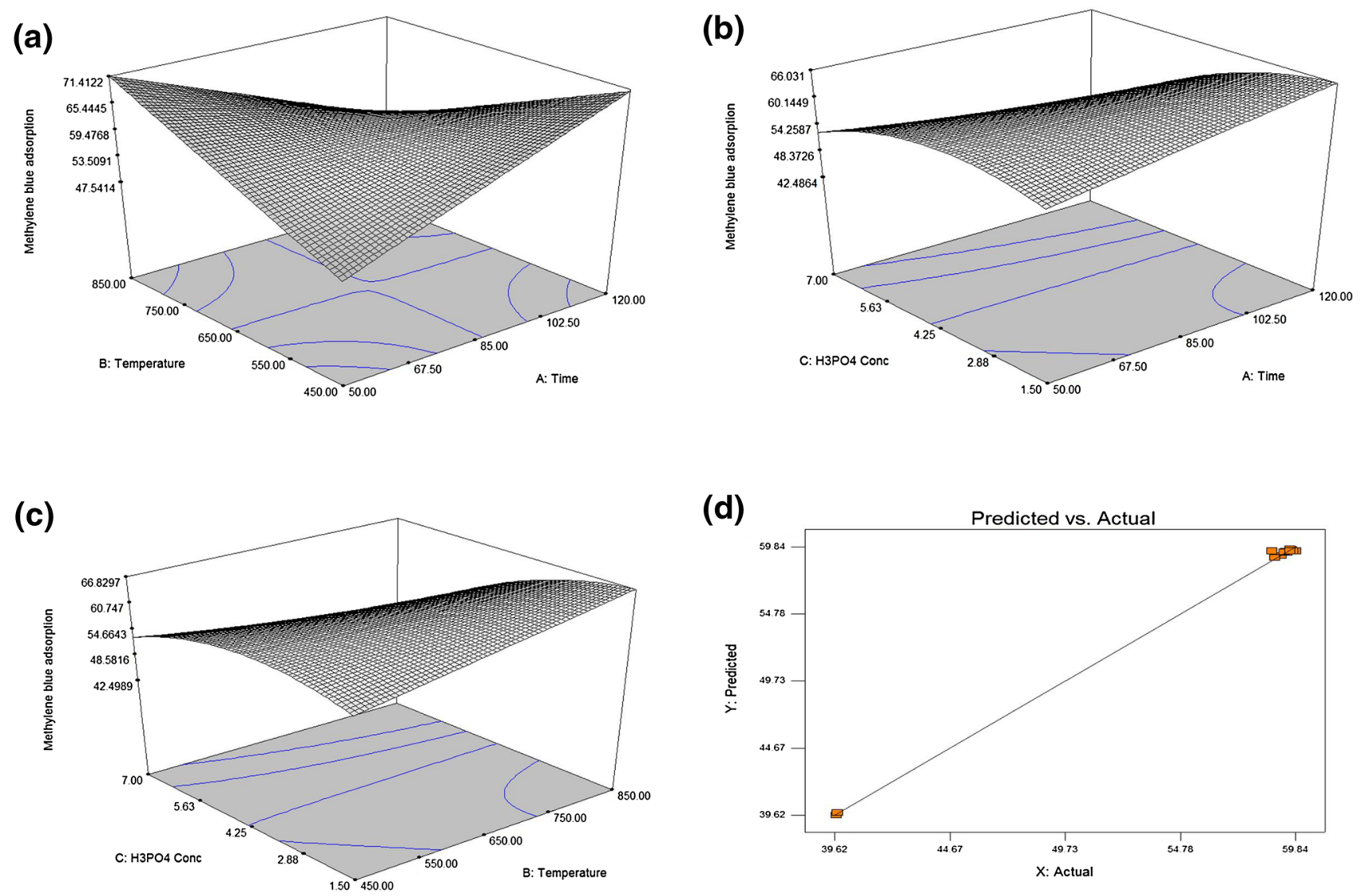

Fig. $23 \mathrm{D}$ plots of a interaction of time and temperature, $\mathbf{b}$ interaction of time and $\mathrm{H}_{3} \mathrm{PO}_{4}$ concentration, $\mathbf{c}$ interaction of temperature and $\mathrm{H}_{3} \mathrm{PO}_{4}$ concentration, $\mathbf{d}$ actual vs model predicted adsorption capacity plot 


\section{Effect of activation time and activating agent concentration}

The interaction of activation time and $\mathrm{H}_{3} \mathrm{PO}_{4}$ concentration at a fixed temperature $\left(650^{\circ} \mathrm{C}\right)$ on the adsorption capacity of the banana trunk-activated carbon is shown Fig. $2 b$. The curve lines in contour plot, and curvy 3D plot shows that the interaction of variables is quadratic. The methylene blue adsorption achieved its maximum value, $66.0 \mathrm{mg} / \mathrm{g}$ when the activation time reached to $120 \mathrm{~min}$. At lower concentration of phosphoric acid and increase of activation time, the resultant activated carbons have gradually increase adsorption capacity against methylene blue; whereas, an increase in activating agent concentration with increase in time decrease the adsorption capacity of the activated carbon against methylene blue dye. At the minimum time of activation, when we increased the activating agent concentration, initially the adsorption capacity of the prepared activated carbon increased and reached to a maximum at middle concentration and was falling with the further rise of concentration. When the activated carbon was prepared with a maximum activating agent concentration $(7.0 \mathrm{~mol} / \mathrm{L})$ and a minimum activating time (50 $\mathrm{min}$ ), the resultant activated carbon was achieved only $52.2 \mathrm{mg} / \mathrm{g}$ adsorption capacity. The banana trunk-activated carbon prepared with $7.00 \mathrm{~mol} / \mathrm{L}$ phosphoric acid with increasing contact time had low adsorption capacity activated carbons. This is because the interaction of phosphoric acid with the chemical constituents of banana trunk required some time to form a stable complex at a certain temperature. With the increase of activation time and $\mathrm{H}_{3} \mathrm{PO}_{4}$ concentration, the adsorption capacity increased till mid concentration value of $\mathrm{H}_{3} \mathrm{PO}_{4}$, after that adsorption capacity decreased due to excess of chemical agent.

\section{Effect of activation temperature and activating agent concentration}

Interaction of activation temperature and activating agent concentration at fixed activation time $(85 \mathrm{~min})$ on the adsorption capacity of the banana truck-activated carbon is shown in Fig. 2c. The activated carbon from banana trunk prepared under these conditions can achieve a maximum adsorption capacity of $66.8 \mathrm{mg} / \mathrm{g}$ against methylene blue dye. The activated carbon prepared at maximum temperature $\left(850^{\circ} \mathrm{C}\right)$ and minimum activating agent concentration $(1.50 \mathrm{~mol} / \mathrm{L})$ can achieve maximum adsorption capacity $(66.8 \mathrm{mg} / \mathrm{g})$. This result conveys that the banana trunk-activated carbon prepared at the highest activation temperature and with the lowest phosphoric concentration will be suitable for removal of methylene blue with a high adsorption capacity. The banana trunk-activated carbon prepared at low activation temperature $\left(450^{\circ} \mathrm{C}\right)$ and high phosphoric acid concentration can have adsorption capacity, $53.2 \mathrm{mg} / \mathrm{g}$. The activated carbons prepared at high activation temperature $\left(850{ }^{\circ} \mathrm{C}\right)$ and with high $\mathrm{H}_{3} \mathrm{PO}_{4}$ concentration $(7.0 \mathrm{~mol} / \mathrm{L})$ can have adsorption capacity around $42.5 \mathrm{mg} / \mathrm{g}$ for methylene blue adsorption.

Therefore, to produce an efficient activated carbon from the banana trunk that has a high adsorption capacity, it is advised to use a low concentration of phosphoric acid. Using a high concentration of phosphoric acid would decrease adsorption capacity of banana trunk-activated carbon against methylene blue dye. At the same time, other factors activation time and activation temperature also played a significant role in the production of high adsorption capacity activated carbons. The predicted and experimental values of the adsorption capacity for banana trunk-activated carbons are represented in Fig. 2d. However, the activated carbon can also achieve a high adsorption capacity only when optimum activation time, activation temperature, and activating agent concentration were used.

\section{Response surface methodology optimization}

It is recommended to use the desirability function to optimize the operating variables with output responses. Since, in this experiment we set only one output response, so desirability must be 1 as shown in Table 4. It is widely used method for optimizing operating variables for a maximizing response. The range of desirability function for two or more responses lies between 0 and 1 . In case of two responses as output, the desirability value for any of the response achieve 0 indicates that the characteristics of the selected responses are not reasonable; whereas, the desirability value of 1 for any response indicates that all process characteristics responses are possible (Prakash et al. 2009; Danish et al. 2014b). The goal of optimization in this experiment was to keep the activation time, activation temperature, and activating agent concentration within the range and maximizing the adsorption capacity of the activated carbon. To achieve maximum desirability (1.000) shown in Table 4, all the three parameters were fixed within the range. With the maximum desirability, it was found the model predicted adsorption capacity, $64.66 \%$ as shown in Table 4.

The graphical representations of the desirability for higher adsorption capacity are shown in Fig. 3a-c. From

Table 4 The optimum conditions for preparation banana trunk-activated carbon and the percentage adsorption capacity of the predicted result for prepared activated carbon

\begin{tabular}{|c|c|c|c|c|}
\hline & \multicolumn{3}{|c|}{ Parameters } & \multirow{3}{*}{$\begin{array}{l}\text { Response } \\
\text { Adsorption capacity } \\
\text { Predicted }(\mathrm{mg} / \mathrm{g})\end{array}$} \\
\hline & $X_{1}$ & $X_{2}$ & $X_{3}$ & \\
\hline & $\min$ & ${ }^{\circ} \mathrm{C}$ & $\mathrm{mol} / \mathrm{L}$ & \\
\hline Optimized value & 50.53 & 774 & 5.09 & 64.66 \\
\hline
\end{tabular}


Fig. 3 Desirability plots for maximum adsorption capacity of banana trunk-activated carbon
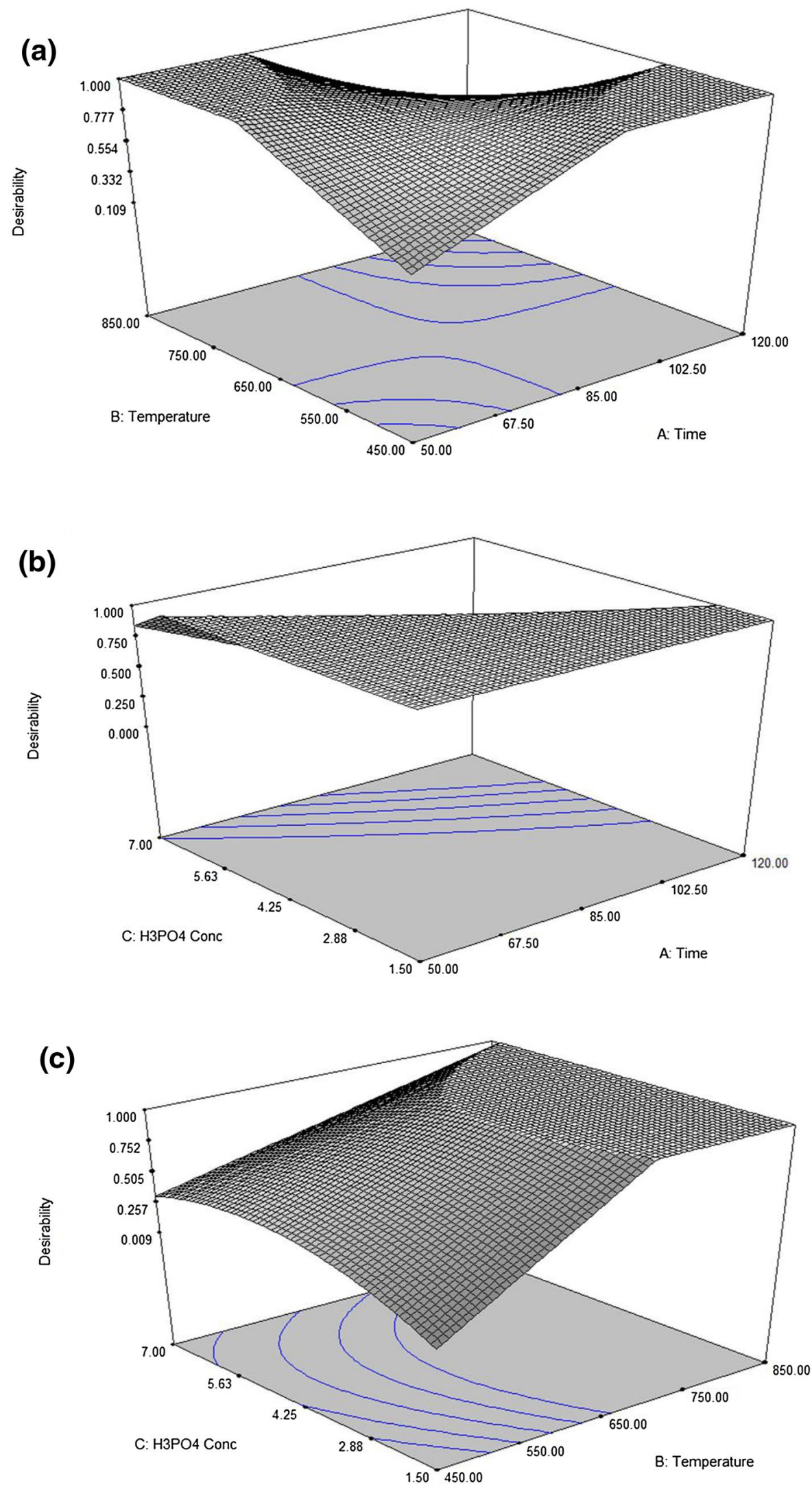
Fig. 3a, the maximum desirability lies near maximum temperature or maximum time; in Fig. $3 \mathrm{~b}$ the maximum desirability lies near low activating agent concentration and extended uniformly over the time axis. This implies that at low concentration of $\mathrm{H}_{3} \mathrm{PO}_{4}(1.5 \mathrm{~mol} / \mathrm{L})$ and minimum time of activation ( $50 \mathrm{~min}$ ), desirable activated carbon for efficient methylene blue removal capacity $(64.66 \mathrm{mg} / \mathrm{g})$ can be achieved. In Fig. 3c, the desirability shifted towards higher temperature of activation. At a low temperature of activation, the concentration of activating agent does not make any difference at fixed activation time (85 min.); therefore, we cannot achieve desired activated carbon with high adsorption capacity. Comparison of adsorption capacities of various biomass waste derived adsorbents and their adsorption equilibrium time and adsorbent dosage for effective methylene blue removal have been reported in Table 5.

\section{Activated carbon characterizations}

Fourier transform infrared spectroscopic (FTIR) study of sample was conducted on Nicolet 6700 at instrumentation lab, school of environmental science and engineering Shanghai Jiao Tong University, shanghai, PRC. The spectrum was taken with $\mathrm{KBr}$ pellets method. The spectrum of activated carbon sample of run number 3 was shown in Fig. 4. The dominated peaks were observed at 3421, 2360, 1579, 1400, 1288,1150 , and $1095 \mathrm{~cm}^{-1}$ due to presence of normal polymeric - $\mathrm{OH}$ stretching, multiple bonding between carbon and nitrogen, aromatic nitrogen containing compounds, $\mathrm{C}-\mathrm{H}$ in

Table 5 Comparison of the methylene blue adsorption capacities by various agricultural waste and by-products

\begin{tabular}{lclll}
\hline Adsorbent & $\begin{array}{l}\text { Methylene blue } \\
\text { removal capacity } \\
(\mathrm{mg} / \mathrm{g})\end{array}$ & $\begin{array}{l}\text { Adsorbent } \\
\text { dosage }(\mathrm{g} / \mathrm{L})\end{array}$ & Contact time & References \\
\hline Banana trunk-activated carbon & 59.5 & 2.5 & $50 \mathrm{~min}$ & This study \\
Neem leaf powder & 8.76 & 2.0 & $5 \mathrm{~h}$ & Bhattacharyya and Sharma (2005) \\
Vetiver root steam-activated carbon & 375 & 0.2 & $48 \mathrm{~h}$ & Altenor et al. (2009) \\
Vetiver root phosphoric acid-activated carbon & 423 & 0.2 & $48 \mathrm{~h}$ & Altenor et al. (2009) \\
Sulfuric acid-treated Indian rosewood sawdust (SDC) & 56.4 & 2.0 & $120 \mathrm{~min}$ & Garg et al. (2004) \\
Formaldehyde- treated Indian rosewood sawdust & 31.1 & 2.0 & $120 \mathrm{~min}$ & Garg et al. (2004) \\
Rattan sawdust-activated carbon & 294.14 & 1.0 & $24 \mathrm{~h}$ & Hameed et al. (2007a) \\
Bamboo-activated carbon & 454.2 & 1.0 & $48 \mathrm{~h}$ & Hameed et al. (2007b) \\
Walnut shell-activated carbon & 315 & 4.0 & $24 \mathrm{~h}$ & Yang and Qui (2010) \\
Wheat shells & 21.50 & 0.5 & $75 \mathrm{~min}$ & Bulut and Aydin (2006) \\
Activated coir pith carbon & 5.87 & 2.0 & $100 \mathrm{~min}$ & Kavitha and Namasivayam (2007) \\
Sunflower oil cake-activated carbon & 16.43 & 2.0 & $24 \mathrm{~h}$ & Karagöz et al. (2008) \\
\hline
\end{tabular}

Fig. 4 Fourier transform infrared (FTIR) spectrum of banana trunk-activated carbon (run number 3)

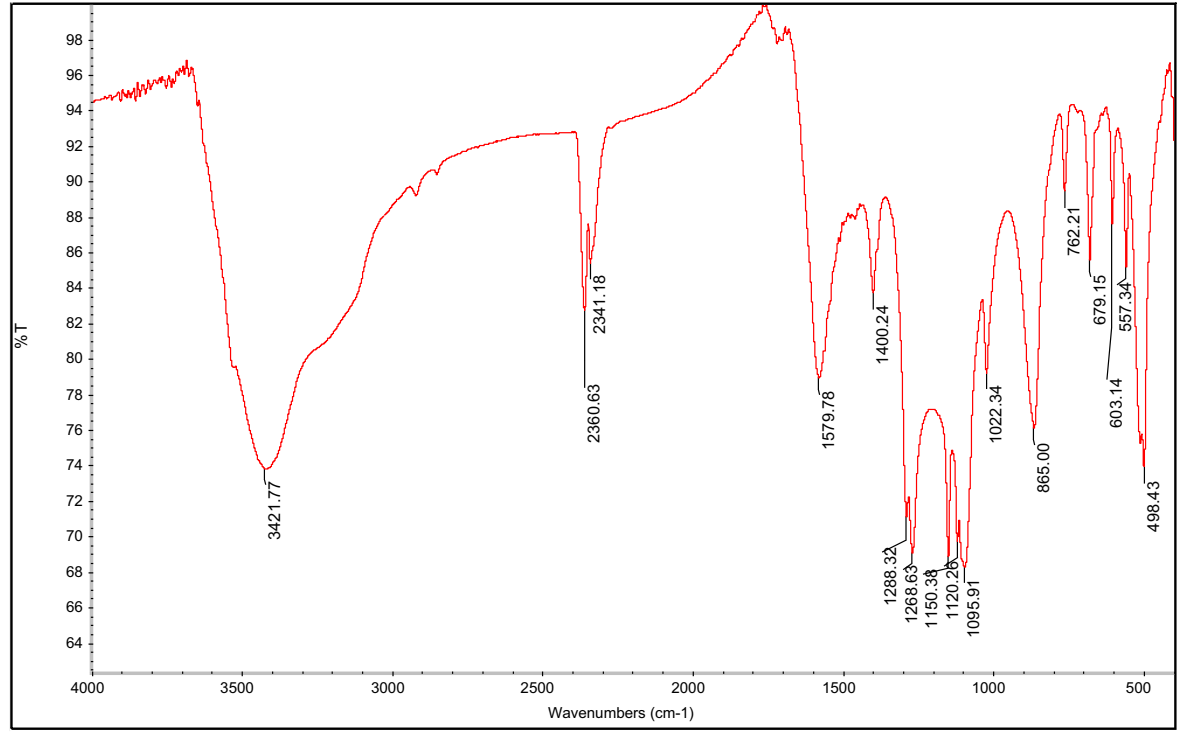


Fig. 5 Powder X-ray diffraction pattern of banana trunk-activated carbon (run number 3 )

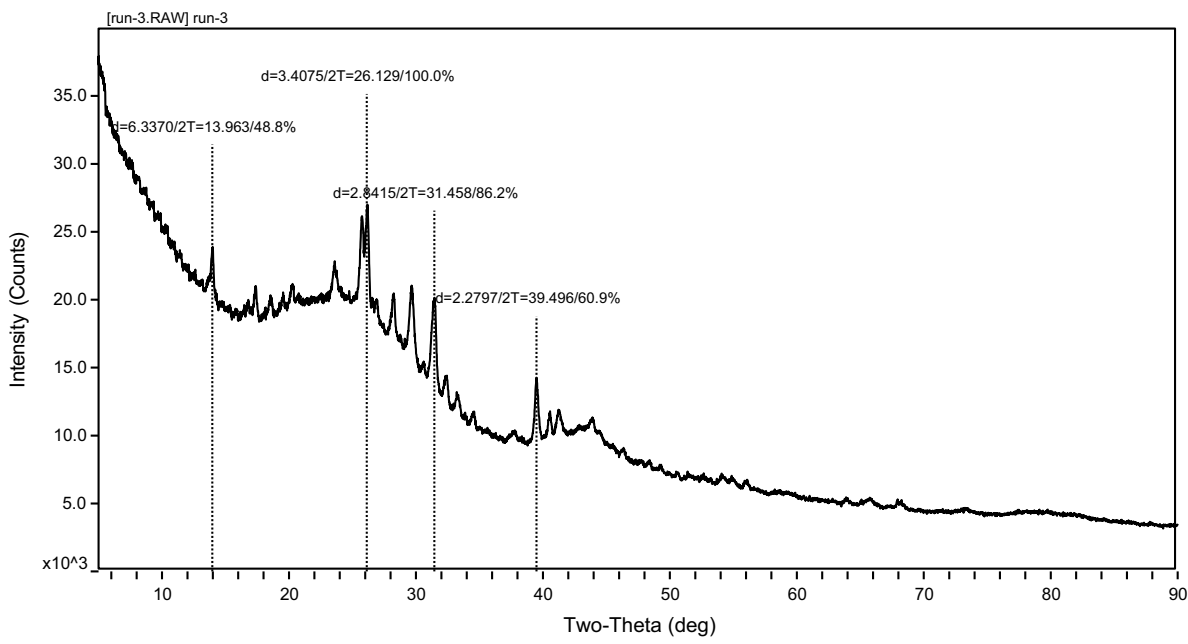

plane bending, aromatic secondary amines, $-\mathrm{CN}$ stretching, and organic siloxane ( $\mathrm{Si}-\mathrm{O}-\mathrm{Si}$ ) vibrations, respectively. The CHNS analysis was conducted on German Vario Macro Cube at Instrumentation Center, School of Environmental Science and Engineering Shanghai Jiao Tong University, shanghai, PRC. The results of the banana trunk-activated carbon (run number 3) sample analysis revealed that it contains around $59.65 \%$ carbon, $2.01 \%$ hydrogen, $0.59 \%$ nitrogen, and $0.005 \%$ sulfur atoms. Powder X-ray diffraction (XRD) was conducted on Shimadzu XRD-6100 diffractometer, the obtained diffraction pattern for activated carbon sample (run number 3) shown in Fig. 5. The XRD spectra revealed that crystal lattice at $2 \theta 26.19^{\circ}$ have lattice indices (110) and distance between the lattice point $3.40 \AA$. The field emission electron microscope made up of Hitachi JEOL JSM-7800F Prime, at instrumentation center, Shanghai Jiao Tong University, shanghai, PRC, was used for surface image of banana trunk-activated carbon (run number 3) sample shown in Fig. 6, the surface of the activated carbon at magnification $50000 \times$ showing highly rough surface, the fractal dimension of the surface is less than $1 \mu \mathrm{m}$ which seems to be suitable for trapping the methylene blue dye molecules.

\section{Conclusion}

The optimization of the banana trunk-activated carbon preparation conditions such as activating agent concentration $\left(\mathrm{H}_{3} \mathrm{PO}_{4}\right)$, activation time, and temperature was done to achieve better activated carbon for methylene blue removal. The central composite design of response surface methodology (RSM) approach was used, and the adsorption capacity of activated carbon was calculated as a response. The optimum points for activation time, activation temperature, and $\mathrm{H}_{3} \mathrm{PO}_{4}$ concentration was found to be $51 \mathrm{~min}, 774{ }^{\circ} \mathrm{C}$, and $5.09 \mathrm{~mol} / \mathrm{L}$, respectively. Under these conditions, the

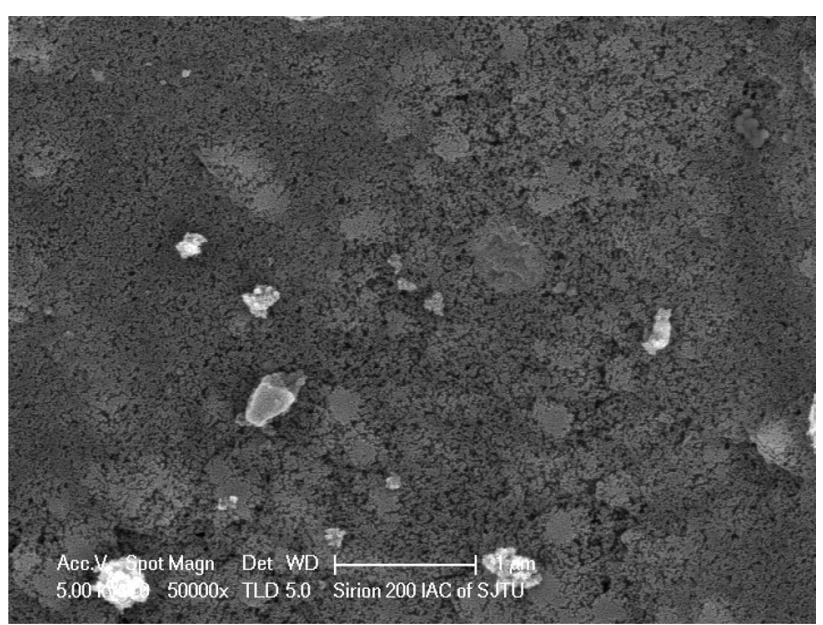

Fig. 6 Field emission scanning electron microscopy of the banana trunk-activated carbon (run number 3)

activated carbon prepared from banana trunk should have maximum adsorption capacity of $64.66 \mathrm{mg} / \mathrm{g}$.

Open Access This article is distributed under the terms of the Creative Commons Attribution 4.0 International License (http://creativecomm ons.org/licenses/by/4.0/), which permits unrestricted use, distribution, and reproduction in any medium, provided you give appropriate credit to the original author(s) and the source, provide a link to the Creative Commons license, and indicate if changes were made.

\section{References}

Ahmad F, Daud WMAW, Ahmad MA, Radzi R (2012) Cocoa (Theobroma cacao) shell-based activated carbon by $\mathrm{CO}_{2}$ activation in removing of cationic dye from aqueous solution: kinetics and equilibrium studies. Chem Eng Res Des 90(10):1480-1490 
Alam MZ, Muyibi SA, Toramae J (2007) Statistical optimization of adsorption processes for removal of 2,4-dichlorophenol by activated carbon derived from oil palm empty fruit bunches. J Environ Sci 19:674-677

Altenor S, Carene B, Emmanuel E, Lambert J, Ehrhardt J-J, Gaspard $S$ (2009) Adsorption studies of methylene blue and phenol onto vetiver roots activated carbon prepared by chemical activation. J Hazard Mater 165:1029-1039

Auta M, Hameed BH (2011) Optimized waste tea activated carbon for adsorption of methylene blue and acid blue 29 dyes using response surface methodology. Chem Eng J 175:233-243

Azargohar R, Dalai AK (2005) Production of activated carbon from Luscar char: experimental and modeling studies. Microporous Mesoporous Mater B 85:219-225

Bestani B, Benderdouche N, Benstaali B, Belhakem M, Addou A (2008) Methylene blue and iodine adsorption onto an activated desert plant. Bioresour Technol 9:8441-8444

Bhattacharya KG, Sharma A (2005) Kinetics and thermodynamics of methylene blue adsorption on neem (Azadirachta indica) leaf powder. Dyes Pigments 65(1):51-59

Bhattacharyya KG, Sharma A (2005) Kinetics and thermodynamics of methylene blue adsorption on Neem (Azadirachta indica) leaf powder. Dyes Pigments 65:51-59

Bulut Y, Aydin H (2006) A kinetics and thermodynamics study of methylene blue adsorption on wheat shells. Desalination 194:259-267

Danish M, Hashim R, Ibrahim MNM, Rafatullah M, Ahmad T, Sulaiman O (2011) Characterization of Acacia mangium wood based activated carbons prepared in the presence of basic activating agents. Bioresources 6(3):3019-3033

Danish M, Hashim R, Ibrahim MNM, Sulaiman O (2014a) Response surface methodology approach for methyl orange dye removal using optimized Acacia mangium wood activated carbon. Wood Sci Technol 48:1085-1105

Danish M, Hashim R, Ibrahim MNM, Sulaiman O (2014b) Optimized preparation for large surface area activated carbon from date (Phoenix dactylifera L.) stone biomass. Biomass Bioenergy 61:167-178

Garg VK, Amita M, Kumar R, Gupta R (2004) Basic dye (methylene blue) removal from simulated wastewater by adsorption using indian rosewood sawdust: a timber industry waste. Dyes Pigments 63:243-250

Ghaedi AM, Ghaedi M, Vafaei A, Iravani N, Keshavarz M, Rad M, Tyagi I, Agarwal S, Gupta VK (2015) Adsorption of copper(II) using modified activated carbon prepared from pomegranate wood: optimization by bee algorithm and response surface methodology. J Mol Liq 206:195-206

Ghosh D, Bhattacharyya KG (2002) Adsorption of methylene blue on kaolinite. Appl Clay Sci 20:295-300

Guo J-Z, Li B, Liu L, Lv K (2014) Removal of methylene blue from aqueous solutions by chemically modified bamboo. Chemosphere 111:225-231

Hameed BH, Ahmad AL, Latiff KNA (2007a) Adsorption of basic dye (methylene blue) onto activated carbon prepared from rattan sawdust. Dyes Pigments 75:143-149
Hameed BH, Din ATM, Ahmad AL (2007b) Adsorption of methylene blue onto bamboo-based activated carbon: kinetic and equilibrium studies. J Hazard Mater 141:819-825

Hasan SH, Srivastava P (2011) Biosorptive abatement of Cd(II) by water using immobilized biomass of Arthrobacter sp.: response surface methodological approach. Ind Eng Chem Res 50(1):247-258

Jaiswal N, Prakash O, Talat M, Hasan SH, Pandey RK (2011) Application of response surface methodology for the determination of optimum reaction conditions (Temperature and $\mathrm{pH}$ ) for starch hydrolysis by $\alpha$-amylase. Asian J Biochem 6:357-365

Karacan F, Ozden U, Karacan S (2007) Optimization of manufacturing conditions for activated carbon from Turkish lignite by chemical activation using response surface methodology. Appl Therm Eng 27:1212-1218

Karagöz S, Tay T, Ucar S, Erdem M (2008) Activated carbons from waste biomass by sulfuric acid activation and their use on methylene blue adsorption. Bioresour Technol 99:6214-6222

Kavitha D, Namasivayam C (2007) Experimental and kinetic studies on methylene blue adsorption by coir pith carbon. Bioresour Technol 98(1):14-21

Malik PK (2003) Use of activated carbons prepared from sawdust and rice-husk for adsorption of acid dyes: a case study of acid yellow 36. Dyes Pigments 56(3):239-249

Okman I, Karagöz S, Tay T, Erdem M (2014) Activated carbons from grape seeds by chemical activation with potassium carbonate and potassium hydroxide. Appl Surf Sci 293:138-142

Oliveira LC, Pereira E, Guimaraes IR, Vallone A, Pereira M, Mesquita JP, Sapag K (2009) Preparation of activated carbons from coffee husks utilizing $\mathrm{FeCl}_{3}$ and $\mathrm{ZnCl}_{2}$ as activating agents. J Hazard Mater 165(1-3):87-94

Prakash O, Talat M, Hasan SH (2009) Response surface design for the optimization of enzymatic detection of mercury in aqueous solution using immobilized urease from vegetable waste. J Mol Catal B Enzym 56(4):265-271

Ranjan D, Mishra D, Hasan SH (2011) Bioadsorption of arsenic: an artificial neural networks and response surface methodology approach. Ind Eng Chem Res 50(17):9852-9863

Sych N, Trofymenko SI, Poddubnaya OI, Tsyba MM, Sapsay VI, Klymchuk DO (2012) Porous structure and surface chemistry of phosphoric acid activated carbon from corncob. Appl Surf Sci 261:75-82

Valente Nabais J, Laginhas C, Ribeiro Carrott MML, Carrott PJM, Crespo Amoros JE, Nadal Gisbert AV (2013) Surface and porous characterization of activated carbons made from a novel biomass precursor, the esparto grass. Appl Surf Sci 265:919-924

Yang J, Qui K (2010) Preparation of activated carbon from walnut shells via vacuum chemical activation and their application for methylene blue removal. Chem Eng J 165(1):209-217

Publisher's Note Springer Nature remains neutral with regard to jurisdictional claims in published maps and institutional affiliations. 